\title{
Role of Mesenchymal Stem Cells In Chronic Obstructive Lung Disease
}

\author{
Fatmi Andari, Triya Damayanti \\ Department of Pulmonology and Respiratory Medicine, Faculty of Medicine Universitas Indonesia, \\ Persahabatan Hospital, Jakarta
}

\begin{abstract}
Corresponding Author:
Triya Damayanti| Departement of Pulmonology and Respiratory Medicine, Faculty of Medicine Universitas Indonesia, Persahabatan Hospital, Jakarta | tria_94@yahoo.com
\end{abstract}

Submitted: February $19^{\text {th }}, 2021$

Accepted: March $24^{\text {th }}, 2021$

Published: June $23^{\text {th }}, 2021$

Respir Sci. 2021; 1(3): 202-212

https://doi.org/10.36497/respirsci.v1i3.26

\begin{abstract}
Therapy for Chronic Obstructive Pulmonary Disease (COPD) is currently still not giving effect to tissue repair and regeneration. Chronic Obstructive Pulmonary Disease is still a progressive degenerative disease. Stem cells through their regenerative ability offer a new promising alternative therapy for the management of degenerative diseases including COPD. There have been many studies conducted to determine the safety and efficacy of stem cells in COPD. Published research about stem cells on COPD is still in phase II. Further research is needed on a larger scale before stem cells can be widely applied in the management of COPD. Stem cells are a very promising alternative therapy and are a big leap in the medical world for degenerative diseases including COPD.
\end{abstract}

Keywords: stem cell, COPD, emphysema

\section{INTRODUCTION}

Research on stem cells has rapidly developed in the last 30 years. Stem cells are used by many scientists to study the growth and development process in human tissues and its link with the pathogenesis of the degenerative disease. Stem cells become hope in the medical field as an alternative therapy for diseases unable to be handled by conservative means. Other than its benefits in degenerative diseases, it's not unlikely that in the future stem cells may contribute more in medicine. ${ }^{1,2}$

Research and development of stem cells are often related to issues regarding ethics and religion. Stem cells offer a beneficial economic value if made to be an option of therapy for diseases unable to be treated by conventional therapies, although many controversies also follow. Clinics and health centers offering stem cell application in medicine have been available for the last 20 years. America, Germany, Korea, Thailand and Ukraine have started offering stem cell business to treat many diseases such as diabetes, multiple sclerosis, autism, aging and heart failure. ${ }^{2}$

Data by World Health Organization (WHO) shows that Chronic Obstructive Pulmonary Disease (COPD) is responsible for the fifth cause of global death in 2002 and has risen to be the third in the year 2016. Previously WHO predicted that the 
third rank will be reached by 2030 . This disease causes about 3 billion deaths worldwide. The figure might increase with longer life expectancy and smoking populations. COPD is marked by lung parenchyma inflammation which causes parenchymal structure damage. Choices of therapy currently available have yet to be able to prevent progressivity and restore tissue damage found in COPD. Stem cell therapy is a big stepping stone in the medical world for degenerative diseases, including COPD. ${ }^{3}$

\section{CHRONIC OBSTRUCTIVE PULMONARY DISEASE}

One of the non-communicable diseases that becomes an important issue in Indonesia and the world is COPD. The Asia Pacific COPD Round Table Group estimates the number of COPD patients in the Asia Pacific reaches $\mathbf{5 6 . 6}$ million in the year 2006. In Indonesia, there are approximately 4.8 million COPD patients with a prevalence rate of $5.6 \%$. The figure may rise with the escalating number of smokers. Several factors influence the increasing number of COPD patients, such as smoking habits, population growth, longer life expectancy, industrialization and pollution. ${ }^{3}$

Based on Global Initiative for Chronic Obstructive Lung Disease (GOLD) 2019, COPD is a disease marked by airflow limitation which is persistent, progressive, and related to the chronic process of inflammation as a response to gas and dangerous substance exposure. Some risk factors of COPD are cigarette smoke, air pollution, recurrent airway infection, socioeconomic condition, lung growth and development, genetics, and gender. Airflow limitation in COPD is caused by an obstruction in the small airway (bronchiolitis obstruction) and parenchymal damage (emphysema) due to the chronic process of inflammation. ${ }^{3,4}$

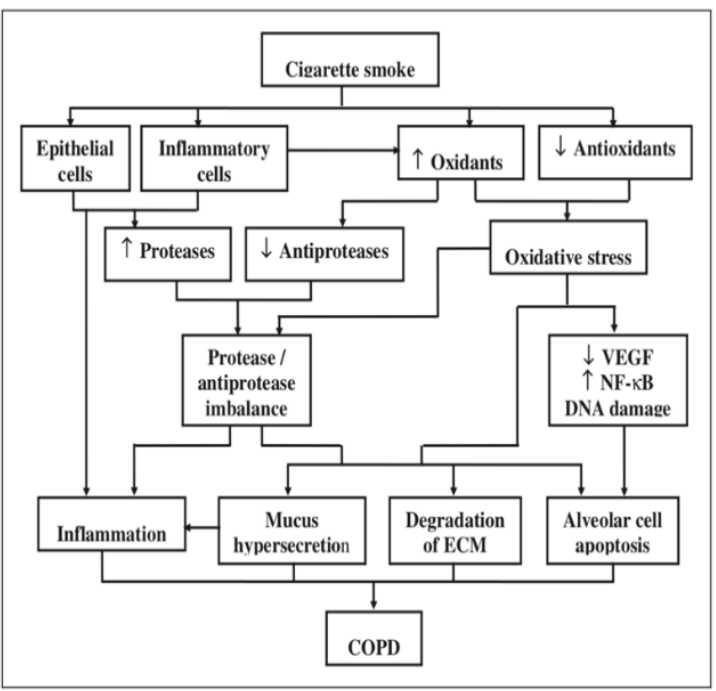

Figure 1. Scheme of COPD pathogenesis ${ }^{4}$

Inflammatory cells involved in COPD are neutrophil, macrophage, $T$ lymphocyte $\left(\mathrm{T} / \mathrm{CD}^{+}\right.$cell and $\mathrm{T} 8 / \mathrm{CD} 8^{+}$cell), B lymphocyte, eosinophil and epithelial cell. The cells release mediators of inflammation such as B4 leukotriene, tumor necrosis factor-a (TNF- $a)$, interleukin-1 $\beta$ (IL-1 $\beta$ ), interleukin-6 (IL-6), and tumor growth factor- $\beta$ (TGF- $\beta)$. The process of inflammation causes alveolar damage, airway fibrosis, mucus hypersecretion and release of protease enzyme. Other than inflammation, oxidative stress is also an important mechanism in the development of COPD. Oxidant substances produced by cigarette smoke and pollutants activate an inflammatory gene, inactivates 
antiprotease enzyme, stimulates mucus secretion and plasma exudation. The final product of the ongoing process is airflow limitation and air trapping (Figure 1). ${ }^{3,4}$

\section{STEM CELLS}

Stem cells are cells that do not differentiate or have not differentiated. Stem cells have the potential to develop into various types of human tissues. Stem cells are the base cells of all multicellular organisms. Stem cells have clonogenic properties or proliferative ability and form an abundant amount of cell colonies from just a single cell. Stem cells have some characteristics such as the ability to reproduce and self-renew, differentiate into various types of functional cell, capability to survive for a long time in proper condition, and the cells activity can be influenced by the external environment. 5,6

In the last few decades, scientists have researched the biological aspects of stem cells to learn ways to develop them and find a new method to overcome health problems in the medical field. Researchers and doctors hope to discover a new concept of stem cells that may become a huge breakthrough as therapy for current health problems. Several studies are done to find the most effective method to utilize stem cells in treatments. Stem cell-based therapy has been established as a standard of clinical therapy for several diseases such as leukemia, burn injury, corneal damage and abnormality. ${ }^{5}$
The history of stem cell development begun in the middle of year 1800 . Scientists found a type of cell able to develop into other cells. The first stem cell was discovered in early 1900 as a cell able to develop into a blood cell. The term stem cell was first coined by a Russian histology expert Alexander Maximov in 1908. Hemopoietic stem cells were first discovered in the fetal umbilical cord in 1978. A scientist from Newcastle University was able to grow artificial liver from an umbilical cord embryonic stem cell in 2006. This show that embryonic stem cell is capable of differentiating into more types of the cell compared to adult stem cell. ${ }^{5}$

Stem cells that have not differentiated can develop into 2 identical cells through the process of mitosis. Those cells can then differentiate into various human tissue. Stem cells can be found in almost every multicellular organism. Stem cells are very important for development, growth and repair of brain, bones, muscle, nerve tissue, blood, skin and other organs of the human body. Stem cells are divided into 5 types based on the potential of differentiation, which are totipotent stem cell, pluripotent stem cell, multipotent stem cell, oligopotent stem cell and unipotent stem cell. Stem cells are also classified based on the source into 2 types, which are embryonic stem cells and adult stem cells. ${ }^{5}$

Totipotent stem cells are a type of stem cell able to differentiate into all kinds of cells. Examples of totipotent stem cells include the zygote from the fertilization of egg cells by the sperm and some cells which were the first result of zygote 
division. Pluripotent stem cells can differentiate into almost every type of cell. Examples of pluripotent stem cells are embryonic stem cells and cells from mesodermal, endodermal and ectodermal layers in the early stage of human embryo development. Multipotent stem cell example is hematopoietic stem cell able to differentiate into red blood cell, white blood cell and platelet. The hematopoietic stem cell is a part of the adult stem cell. Oligopotent stem cells can differentiate into some types of cells, such as lymphoid and myeloid stem cells. Other types of stem cell-based on the potential are unipotent stem cells that are only capable of developing into their type. Unipotent stem cells can only develop into similar cells with themselves but can self-repair, therefore replacing damaged tissues. ${ }^{5,7}$

Based on the source, stem cells are divided into embryonic stem cells and adult stem cells. The embryonic stem cell is a stem cell with pluripotent replication ability and able to live for a long duration in proper condition. The embryonic stem cell is found in inner cell mass of blastocyte a few days after zygote development. Different from embryonic stem cells, an adult stem cell has no totipotent properties. Adult stem cells have multipotent properties and are found in certain adult tissues such as umbilical cord or placenta after delivery. The cells can also be found in multiple human tissues after embryonic development. Adult stem cells undergo mitotic multiplication to replace dead cells and repair damaged tissue. The main role of adult stem cell in living organisms is to maintain and repair tissue damage. ${ }^{5}$

In addition to the stem cells mentioned, currently, the third type of stem cell is found, called induced pluripotent stem cell (iPS cells). iPS stem cell is a result of manipulating certain genes that reprogram somatic cells to return to a pluripotent state similar to early human embryonic stage. ${ }^{5,6}$

In the process of stem cell application as therapy for degenerative disease, the stem cell was initially cultured in the laboratory. The culturing process begins by moving cells from the embryo preimplantation phase into a culture plate containing broth. The plate is called culture medium. Stem cells will replicate and spread to the whole surface of the culture medium. Some of the stem cells are moved to a new culture medium after the medium is full. The process is called replating or subculturing. The replating or subculturing process is done repetitively for a few months. The stem cells that have been cultured for 6 months without undergoing proliferation are pluripotent. The cells have normal genetic makeup and are called embryonic stem cells. ${ }^{5}$

The current application of stem cells is to repair damage in tissues unable to repair themselves, therefore body organs can function normally again. Stem cell therapy does not only work by transplanting the stem cells to the body but also prompts the body to keep producing new cells that form healthy tissue. Some applications of stem cells in the medical world include type I diabetes mellitus, 
Parkinson's disease, Huntington disease, celiac disease, heart failure, muscle damage and neurological abnormality. ${ }^{5}$

\section{ROLE OF STEM CELLS IN CHRONIC OBSTRUCTIVE PULMONARY DISEASE}

Based on the Guideline of Diagnosis and Treatment for COPD by The Indonesian Society of Respirology (ISR) year 2016, strategies of COPD management involve 7 aspects, which are education, smoking cessation, medication, rehabilitation, oxygen therapy, mechanical ventilation and nutrition. Medications for COPD therapy based on GOLD are bronchodilators (anticholinergic, beta-2 agonist and xanthine), anti-inflammation of corticosteroid, antioxidant, mucolytic (ambroxol, edosteine and carbocisteine), antitussive and phosphodiesterase-4 inhibitor (PD4 inhibitor). ${ }^{3,4}$

Those drugs can lessen airflow obstruction, decrease the frequency of exacerbation and improve patient's quality of life, but none can prevent progressivity and reduce the number of deaths. Currently, new perspectives regarding COPD therapy have been revealed through the regenerative property of stem cells. Some studies about stem cells explain the biological effect and mechanism of mesenchymal stem cell (MSC) as a novel approach for COPD therapy. ${ }^{3,4}$

Up until now, stem cell as COPD therapy is still under research. A lot of ongoing study about stem cell as COPD therapy has been done. Three studies that started in 2008 have been completed and published. Daniel J Weiss et al researched 62 COPD patients in 2008 to test the safety and side effects of MSC administration. Research subjects were given intravenous allogeneic MSC with $100 \times 10^{6}$ cells/ml dose every month. Every research subject received 4 complete doses for 4 months. The subjects were followed for 2 years. The study found no difference in side effects, frequency of exacerbations and symptoms of worsening on patients that were given MSC compared to placebo. These three studies recruited moderate, severe, or very severe COPD patients. ${ }^{7,8}$

Stessuk, Ribeiro Paes et al did a study in 2009 by administering intravenous stem cells to COPD patients. The study discovered increase of lung function, slowing of tissue degeneration process, improvement of clinical condition enhanced patient's quality of life and no side effects caused. ${ }^{9,10}$

Based on other studies, intravenous MSC administration increase levels of Cluster of Differentiation 31 (CD31) markers. Increased levels of CD31 in the study subjects indicate protective effect and healing response towards tissue damage (Table 1). ${ }^{11}$

Some other researches are still ongoing now. Studies about bone marrowmesenchymal stem cell (BM-MSC) have yet to be published in Iran, Brazil and Russia. Other than BM-MSC, stem cell originating from the adipose cell is starting to be recognized by researchers. 
Table 1. Clinical trial of mesenchymal stem cells in COPD patients. ${ }^{11}$

\begin{tabular}{|c|c|c|c|c|}
\hline $\begin{array}{c}\text { Clinical trial } \\
\text { number }\end{array}$ & Phase & Treatment & $\begin{array}{l}\text { Research } \\
\text { subjects }\end{array}$ & Outcome \\
\hline NCT 00683722 & 2 & $\begin{array}{l}\mathrm{PROCHYMAL}^{\mathrm{TM}} \text {. Bone } \\
\text { marrow (BM) MSCs } \\
\text { allogenic/placebo } 1 \times 10^{8} \\
\text { cells/intravenous } \\
\text { administration. Every } \\
\text { month for } 4 \text { months }\end{array}$ & $\begin{array}{l}62 \text { moderate- } \\
\text { severe COPD } \\
\text { patients }\end{array}$ & $\begin{array}{l}\text { - Patients were followed for } 2 \text { years: } \\
\text { There were no toxicity, death and } \\
\text { serious side effects. } \\
\text { - No significant difference of lung } \\
\text { function or indicator of quality of life. } \\
\text { - Significant decrease of C-reactive } \\
\text { protein (CRP) levels } 1 \text { month after } \\
\text { transplantation. }\end{array}$ \\
\hline NCT 01110252 & 1 & $\begin{array}{l}\text { Autologous BM MSC; } \\
1 \times 10^{8} \text { IV; single dose }\end{array}$ & $\begin{array}{l}4 \text { severe COPD } \\
\text { patients }\end{array}$ & $\begin{array}{l}\text { Patients were followed for } 2 \text { years: } \\
\text { Improvement of spirometry results, } \\
\text { slowing of degeneration process, } \\
\text { patient's clinical improvement and } \\
\text { increased quality of life. }\end{array}$ \\
\hline NCT 01306513 & 1 & $\begin{array}{l}\text { Autologous BM MSC. } \\
1-2 \text { celss/kg IV. }\end{array}$ & $\begin{array}{l}7 \text { severe-very } \\
\text { severe COPD } \\
\text { patients }\end{array}$ & $\begin{array}{l}\text { - No side effect of BM-MSC } \\
\text { administration. } \\
\text { - Increased level of CD31 marker } \\
\text { three times in alveolar septum }\end{array}$ \\
\hline
\end{tabular}

Research regarding the safety and efficacy of adipose-derived stem cell (ADSC) transplantation in COPD has been done in 7 studies based in the United States of America, Mexico, India and Vietnam. The studies are currently in the process of gathering study subjects.

Comparison of efficacy between BMMSC and ADSC has also been studied and is currently unfinished. Comparison of both stem cell's efficacy is done by 2 researches in Brazil and the United States of America. ${ }^{12}$

Another study was done by Le Thi Bich et al in Vietnam using umbilical cordderived mesenchymal stem cells (UCMSCs) which are intravenously infused with $1.5 \times 10^{6} \mathrm{UC}-\mathrm{MSCs} / \mathrm{kg}$ in 20 COPD patients at stages $C$ and $D$ per the Global Initiative for Obstructive Lung Disease (GOLD) classification. Most clinical outcomes remain reduced after 6 months follow up including CRP, Modified Medical Research Council Score, COPD assessment test and number of exacerbations, while the 6MWT score was slightly increased in stage D COPD patients. ${ }^{13}$

A lot of hypotheses has been created regarding stem cell mechanism in the pathogenesis of COPD. Some of those hypotheses have been proven through research towards humans. Other hypotheses are still based on the preclinical stage of trials in experimental animals. Mechanism of repair and stem cell regeneration in COPD includes stem cell suppressing inflammation process, restoring protease-antiprotease enzyme balance, suppressing of the alveolar apoptotic process, suppressing levels of COPD oxidative stress and stem cell having the ability to differentiate as alveolar cells. ${ }^{4}$

\section{MSC Transplantation Suppress Inflammation Process in COPD Pathogenesis}

Cigarette smoke and pollutants activate alveolar macrophage in COPD. Activated alveolar macrophage releases pro-inflammatory cytokines such as TNF-a, 
IL-1 $\beta$ and IL- 6 in the airway and lung parenchyma. Other than pro-inflammatory cytokines, activated macrophage releases chemokines such as IL-8, monocyte chemotactic peptide-1 (MCP-1) and B4 leukotriene that attract neutrophil and $\mathrm{T}$ cell. Activated neutrophil proceeds to release oxidants and protease that contributes towards alveolar destruction and mucus hypersecretion in COPD. T cells especially $\mathrm{CD}^{+}$after being activated will release cytotoxic perforin, granzyme $B$ and TNF-a that directly contribute to the apoptotic process of alveolar epithelial cells. The final stage of the apoptotic process contributes to emphysematous appearance in COPD. ${ }^{4}$

MSC transplantation in COPD patients induces release of antiinflammatory molecules and activates the cellular anti-inflammatory pathway. MSC transplantation suppresses the production of pro-inflammatory mediators such as TNF-a, IL-1 $\beta$, IL- 6 and MCP-1. Based on a study by Weiss et al, intravenous allogeneic MSC administration also decreases CRP levels in COPD patients, although there was no difference in exacerbation frequency between the group that received MSC and the control group. A study with a larger scale is needed to learn the effects of MSC in COPD patients more comprehensively. ${ }^{4}$

Hayes et al evaluate inflammation as measured by CRP in 62 moderate to severe COPD patients after given 4 monthly intravenous infusions of either allogeneic MSCs $100 \times 10^{6}$ cells/infusion or vehicle control. They found that with CRP $>4$ there was significant reductions in $\mathrm{FEV}_{1}$ and increases in 6MWT were observed in MSC compared to controls suggest that there is an inflammatory component of the lung disease that may trigger immunomodulatory effects of MSC treatment. ${ }^{14}$

\section{MSC transplantation correlates with the imbalance of protease and antiprotease in the pathogenesis of COPD}

The balance between protease and antiprotease enzyme is needed to maintain normal lung structure. The imbalance of protease and antiprotease enzyme (an increase of protease enzyme or decrease of antiprotease enzyme) can induce degradation of the extracellular matrix. The process causes alveolar wall destruction, alveolar epithelial cell apoptosis and mucus hypersecretion. ${ }^{4}$

A study by Mercer et al stated that the process of inflammation and oxidation caused by cigarette smoke increases the production of protease enzyme and suppresses the activity of a-1 antitrypsin enzyme that has antiprotease properties. This phenomenon explains why cigarette smoke becomes the main risk factor of COPD. ${ }^{4}$

Stem cell transplantation can restore the balance of protease and antiprotease enzyme in the lung. A study by Guan et al demonstrated how MSC administration has the opposite effect with matrix metalloproteinase (MMP)-9 dan MMP-12 enzyme activity in messenger ribonucleic acid (mRNA) and protein level. This mechanism has not been fully understood 
by scientists. Scientists believed that it is an inhibitory effect by MSC towards protease enzyme produced by inflammatory and epithelial cells which are caused by cigarette smoke and pollutants exposure. ${ }^{4}$

\section{MSC transplantation suppresses alveolar apoptosis in COPD}

A balance between the process of apoptosis and cell proliferation is needed to maintain normal lung structure. In COPD there is an imbalance of apoptosis and cell proliferation. An increase of alveolar apoptosis in COPD is not matched by an increase in alveolar proliferation. As a consequence, an emphysematous alveolar structure is formed. The process of apoptosis is influenced by (Vascular Endothelial Growth Factor) VEGF. Reduced activity of VEGF seen in COPD patients and smokers is caused by decreased levels of VEGF and VEGF receptor 2 (VEGFR2) in mRNA and protein level. ${ }^{4}$

MSC transplantation in COPD patients can prevent the process of apoptosis by 3 mechanisms. The first mechanism is how MSC stimulates VEGF secretion and induces VEGFR2 receptors. This prevents apoptosis because, in COPD patients, VEGF and VEGFR2 are inhibited. The second mechanism is explained by Zhen et al in their study, that MSC administration in rats stimulates the anti-apoptotic B-cell lymphoma (Bcl)-2 gene and suppresses apoptotic Bax gene. The third mechanism is how MSC transplantation inhibits alveolar cleaved caspase 3 molecules which are key for cell apoptotic program. ${ }^{4}$

\section{MSC transplantation influences oxidative stress levels in COPD}

Oxidative stress contributes to COPD pathogenesis. Two types of oxidants play a role in COPD development, which are oxidants from outside (exogenous) and from inside (endogenous). The most common exogenous antioxidants are cigarette smoke and inhaled pollutants that reach the lungs. Different from exogenous antioxidants, endogenous oxidants are produced by the metabolic reaction of inflammatory cells that were activated by cigarette smoke. ${ }^{4,13}$

In normal conditions, natural antioxidants in the body maintain and protect cells and alveolar tissue from damage by existing oxidants. Cigarette smoke and pollutants cause an imbalance of antioxidants and oxidants in the body that contribute to COPD pathogenesis. ${ }^{4,13}$

MSC transplantation based on a study by $\mathrm{Li}$ Ji et al can increase the survival rate of rates with lung damage induced by lipopolysaccharide. MSC transplantation lowers malondialdehyde level which is a marker of oxidative stress. MSC also increases heme oxygenase-1 enzymes in the lung. Heme oxygenase- 1 enzyme is a strong antioxidant enzyme and has a protective effect in alveolar cells. Further research is needed to understand more of stem cells' effect on oxidative process in COPD pathogenesis caused by cigarette smoke and pollutants. ${ }^{4}$

The next role of stem cells in COPD pathogenesis is related to their regeneration and differentiation ability. Mesenchymal stem cells transplanted in 
emphysematous lungs can differentiate into alveolar cells even though the type of cell is still unclear. A study by Zhao et al demonstrates how MSC administration in rats induces differentiation of type 1 and/or type 2 alveolar cells through signal activation of Wnt (Wingless/Integrated) pathway. The pathway is a molecular pathway with an important role in shaping organs in embryo development. Although the study by Zhao et al was not done in COPD patients, the chance of stem cell's successful role in the disease's therapy gets higher. ${ }^{4}$

\section{CONTROVERSY OF STEM CELLS ROLE AS THERAPY OF OBSTRUCTIVE LUNG DISEASE}

Through their regenerative capability, stem cells promise a new alternative to COPD management. A lot of research has been done but it still leaves controversy. Stem cells are also not a part of longdiscussed ethical issues. Some aspects of stem cells that became a highlight of ethical aspect are for example the use of stem cells originating from an embryo, gamete cell donor and use of animal oocytes for Somatic Cell Nuclear Transfer (SCNT). Induced Pluripotent Stem Cell is a new type of stem cells that rarely become controversial because it is obtained by induced somatic cells to return to its pluripotent stage. $^{2}$

Studies of stem cell in COPD still has some research limitations that need to be addressed on future research. Some limitations on the current studies are a small number of subjects, the addition of research subject inclusion criteria and the cohort patients were only followed for 2 years. Some studies have been unsuccessful that have weakened the potential efficacy of stem cells in COPD, which is a severe stage of the patients studied may be a major cause of the failure. In addition, to be considered are the sources of MSC and protocol that were used may together have contributed to the results of the studies.

In the coming future, studies with bigger subjects are needed to thoroughly study the efficacy of stem cells and to profile characteristic risk-benefit for COPD patients. A long-term cohort study is also needed to know the side effects and regenerative effects of stem cells. ${ }^{9,10}$ The short period of new blood vessel formation after transplantation and survival rate of exogenous MSC in the recipient's body is also a challenge to modify in the procedure of next research. ${ }^{11,15}$

\section{CONCLUSION}

Systemic stem cell administration appears to be safe and beneficial from the immunomodulatory effect of MSC treatment. However, the clinical efficacy and understanding of underlying molecular mechanisms remain to be elucidated. Further research is needed on a larger scale before stem cells can be widely applied in the management of COPD. Hopefully, MSC could become an alternative therapy for COPD and other degenerative diseases. 


\section{REFERENCES}

1. Watt FM, Driskell RR. The therapeutic potential of stem cells. Philos Trans $R$ Soc $B$ Biol Sci. 2010;365(1537):155-163.

2. Lo B, Parham L. Ethical issues in stem cell research. Endocr Rev. 2009;30(3):204-213.

3. Amin $M$, Yunus $F$, Antariksa $B$, Djajalaksana $\mathrm{S}$, Wiyono $\mathrm{H}$, Sutoyo D. PPOK: Diagnosis Dan Penatalaksanaan. Jakarta: Penerbit UI; 2016.

4. Jin $Z$, Pan $X$, Zhou $K$, et al. Biological effects and mechanisms of action of mesenchymal stem cell therapy in chronic obstructive pulmonary disease. J Int Med Res. 2015;43(3):303-310.

5. Kalra K, Tomar PC. Stem Cell: Basics, Classification and Applications. Am J Phytomedicine Clin Ther. 2014;2(7):919-930.

6. Slack JMW. What is a Stem Cell. In: The Science of Stem Cells. New Jersey: John Wiley \& Sons, Inc; 2018:1-11.

7. Kumar S, Singh N. Stem cells: A new paradigm. Indian $\mathrm{J}$ Hum Genet. 2006;12(1):4-10.

8. Weiss DJ, Casaburi R, Flannery R, LeRoux-Williams $M$, Tashkin DP. A placebo-controlled, randomized trial of mesenchymal stem cells in
COPD. Chest. 2013;143(6):15901598.

9. Stessuk T, Ruiz MA, Greco OT, Bilaqui $A$, Ribeiro-Paes $M J$ de $O$, Ribeiro-Paes JT. Phase I clinical trial of cell therapy in patients with advanced chronic obstructive pulmonary disease: Follow-up of up to 3 years. Rev Bras Hematol Hemoter. 2013;35(5):352-357.

10. Ribeiro-Paes JT, Bilaqui A, Greco OT, et al. Unicentric study of cell therapy in chronic obstructive pulmonary disease/pulmonary emphysema. Int $\mathrm{J}$ COPD. 2011;6(1):63-71.

11. Sun Z, Li F, Zhou X, Chung KF, Wang W, Wang J. Stem cell therapies for chronic obstructive pulmonary disease: Current status of pre-clinical studies and clinical trials. $J$ Thorac Dis. 2018;10(2):1084-1098.

12. Liras A. Future research and therapeutic applications of human stem cells: General, regulatory, and bioethical aspects. J Trans/ Med. 2010;8(1):1-15.

13. Le Thi Bich $P$, Nguyen Thi $H$, Dang Ngo Chau $\mathrm{H}$, et al. Allogeneic umbilical cord-derived mesenchymal stem cell transplantation for treating 
chronic obstructive pulmonary disease: A pilot clinical study. Stem Cell Res Ther. 2020;11(1).

14. Hayes J, Schuster M, Grossman F, Rutman $\mathrm{O}$ Itescu S. Mesenchymal stem cell therapy improves pulmonary function and exercise tolerance in patients with chronic obstructive pulmonary disease (copd) and high baseline inflammation. Cytotherapy. 2020;22(5):S188S189.

15. Antunes MA, Lapa e Silva JR, Rocco PRM. Mesenchymal stromal cell therapy in COPD: From bench to bedside. Int $J$ COPD. 2017;12:3017-3027. 